\title{
Cartographic Approach to Garbage Collection on the Coast of Ngor (Dakar, Senegal)
}

\author{
Ramatoulaye Mbengue ${ }^{1,4}$, Mame Demba Thiam², Hyacinthe Sambou ${ }^{3}$, Bienvenu Sambou ${ }^{3}$, \\ Amadou Tahirou Diaw ${ }^{4}$, Abdoulaye Ndour ${ }^{1}$ \\ ${ }^{1}$ Faculty of Science and Technology, University Cheikh Anta Diop, Dakar, Senegal, Dakar-Fann, Senegal \\ ${ }^{2}$ Institut fondamental d'Afrique Noire, University Cheikh Anta Diop, Dakar, Senegal, Dakar-Fann, Senegal \\ ${ }^{3}$ Institute of Environmental Sciences, Faculty of Science and Technology, University Cheikh Anta Diop in Dakar, Senegal, Dakar-Fann, \\ Senegal \\ ${ }^{4}$ Teaching Laboratory and Geomatics Research, University Campus of Polytechnic High School of Dakar, Dakar-Fann, Senegal
}

\section{Email address:}

mbrama19@gmail.com (R. Mbengue),sambouzeb@yahoo.fr (H. Sambou)

\section{To cite this article:}

Ramatoulaye Mbengue, Mame Demba Thiam, Hyacinthe Sambou, Bienvenu Sambou, Amadou Tahirou Diaw, Abdoulaye Ndour. Cartographic Approach to Garbage Collection on the Coast of Ngor (Dakar, Senegal). American Journal of Environmental Protection.

Vol. 4, No. 4, 2015, pp. 174-181. doi: 10.11648/j.ajep.20150404.11

\begin{abstract}
This paper aims to analyze the dysfunction of the garbage collection on the coast of Ngor through GPS which is the processing of satellite images combined with field surveys. It highlights and analyzes the failures of the waste collection system in Ngor by the techniques of Geographic Information Systems. Some suggestions are propose to improve the overall quality of the waste management service, the quality of the environment and public health. This study sought the issue of management of solid urban waste on the coast of Ngor (Dakar/Senegal) from production to final landfill. Its importance lies in that it highlighted the salient points such as the location of illegal dumping of garbage. The location of collection circuits will enable decision makers to meet the logistical needs and fit into the establishment of a waste management strategy. This study helps strengthen the collection at the household level (which still dump their waste very often in nature) to encourage recycling, recovery for a sustainable environmental management.
\end{abstract}

Keywords: Waste Management, Impact, Environment, Solid waste, Ngor, Cartography

\section{Introduction}

The city of Dakar is one of the municipalities that are facing serious problems in the management of municipal solid waste [1]; [2]; [3]; [4]. The garbage is now provided by the Urban Community of Dakar and the Agglomeration Community of Rufisque [5]; [6]. Despite numerous management efforts made by the Senegalese government and some other institutions, many places of our cities and surrounding areas are still under the weight of waste [7]; [8]. This study is a contribution to improve the understanding of the environment and living conditions of the people in the district of Municipality of Ngor. Waste management has been an environmental problem in Third World countries and Africa in particular for quite a long time [9]. Senegal is not an exception to this situation which is aggravated by the high level of urbanization [10]. Add to this the changes in the consumption patterns that increase the production of waste [11]. Thus, according to the Environmental Code (2001) the waste is "any residue from a process of production, processing or using, any substance, material, product etc. abandoned or which its holder intends to abandonment." The amount of waste varies from country regions and cities [12]; [13]; [14].

In Dakar, the volume of household waste collected was 780 tons per day in 1986. It exceeded the daily 900 tons in 1996. These figures represent only a collection rate of $75 \%$ [15]; [16]. In 2006 the collected volume was 1,200 tons per day. And from August 2006 this amount has doubled due to the cessation of activities AMA Senegal [17]. Today the production of waste in the city of Dakar is estimated at 516 925 tons / day of municipal solid waste [18]. This increase is a corollary of the increase in population due urbanization $(96.16 \%$ in 2002). For better management of waste, the department of Dakar was divided into 19 administrative districts, including 
that of Ngor (Figure 1). In the district of Municipality of Ngor, the production of waste is estimated $10918 \mathrm{~kg}$ or 10.9 tons per day [6].

\section{Study Area}

Ngor is one of 19 towns district of Dakar. It is located at the western end of the head of the peninsula of Cape Verde, between latitudes $14^{\circ} 44^{\prime} 37^{\prime \prime N}$ Nord and longitudes $17^{\circ} 30^{\prime} 53$ " West. The commute Borough Ngor is limited to the west, south and north by the Atlantic Ocean and to the east by the municipalities of the districts of Yoff and Ouakam (Figure 1).

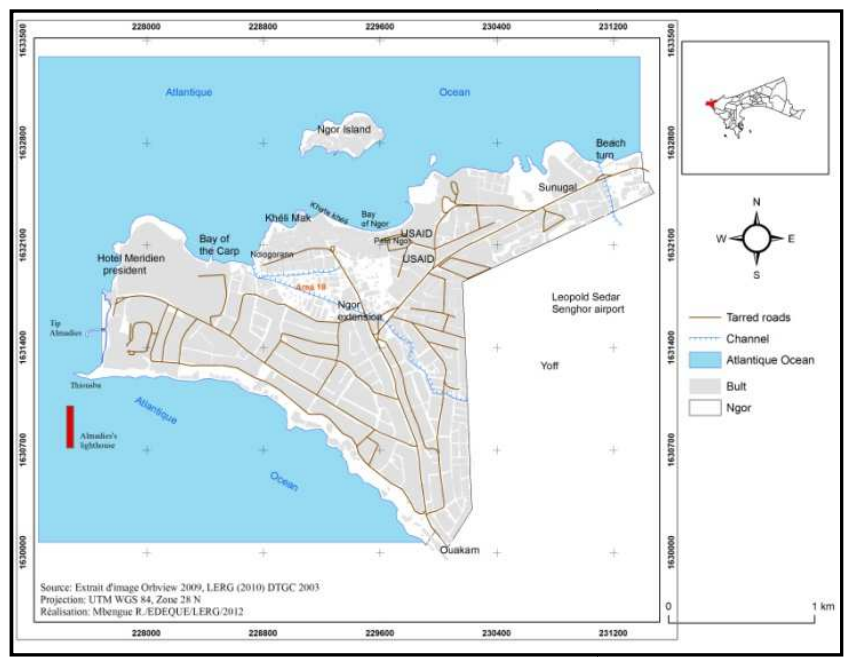

Figure 1. Location of the study area.

Ngor covers a total area 450 ha. The district consists of common Ngor; Ngor village, residential districts known Almadies, turns Ngor and the island of the same name. Ngor village (traditional village) is characterized by compact housing with originally neighborhoods of Grand Ngor Small and Ndiogorann and Ndare (next to the old well Ngadié). However, as part of the consolidation of the sector and Almadies Ndare, services Maps residential areas were divided into 18 areas of Almadies. The zoning performed in this space facilitates addressing services such as the National Telecommunications Company of Senegal, the Post and the Senegalese Water. We have a river system in the town which is rudimentary and is made mainly of streams as Ouaya Diafey, up to the bend at the entrance of Ngor village, Ouaya Ngadié whose outlet is located in the Bay of carp. Indeed, these streams are home today remediation channels. Fishing and tourism are the main activities in the study area.

\section{Materials and Methods}

The methodology used to achieve the expected results, began by a direct field observation in order to get an overview of the solid waste situation in the study area. In Ngor we can fine many housekeepings in one house. In a random method, 203 houses were chosen. Then, a questionary was developed and administered to one household per home; that allowed us to have informations on the management of waste solid in the study zone. An interview guide was also used with municipal authorities to understand how they manage the household solid waste. The collected data were processed with SPSS and Excel. With the GPS (Global Position System) we have previously drawn collectors circuit to determine the different dealer intervention areas, the wild deposits and well-structured collection points and the main trajectory Ngor-Mbeubeuss to forward waste in the ultimate garbage dump. A 2012 Quick Bird image was used for this work because it offer better accuracy. That image has been scanning using the Arc GIS software. Scanning is completed by taking GPS surveys conducted in our various field visits. Quick Bird image allowed us to materialize the waste management state in the municipality district of Ngor. Finally.

\section{Results}

\subsection{Packaging Waste Home}

After waste product, it is stored in bins or said conventional regulatory and users containers (buckets, bowls, bags, wooden crates, metal or plastic drums) or stored on the floor (lots of filth). These containers are for the most part damaged. A bin is a varied form of container (box, crate, cylinder etc.); for receiving waste, including household waste. The use of regulatory bins helps avoid overcrowding of waste in streets and facilitate garbage collection. In the home, it saves from animal intrusions. We noted the use of regulatory bins in residential neighborhoods. They cost between 2,500 and 3,000 CFA Francs. Most respondents say that the garbage can prevent the spread of odors but also microbes. When they are closed flies, cockroaches and others will not come to the garbage. Places of dump bins vary from one house to another. There are some households that rank them in a corner of the house while others leave them outside the house. The use of regulatory bins is more common in residential areas. Thus, we identified households that own more of the bin a plastic bag (Figure 2) is inserted inside. They say plastic bags facilitate the evacuation of refuse during collection. It is also a precaution to facilitate maintenance. In the island of Ngor, all households surveyed have regulatory garbage.

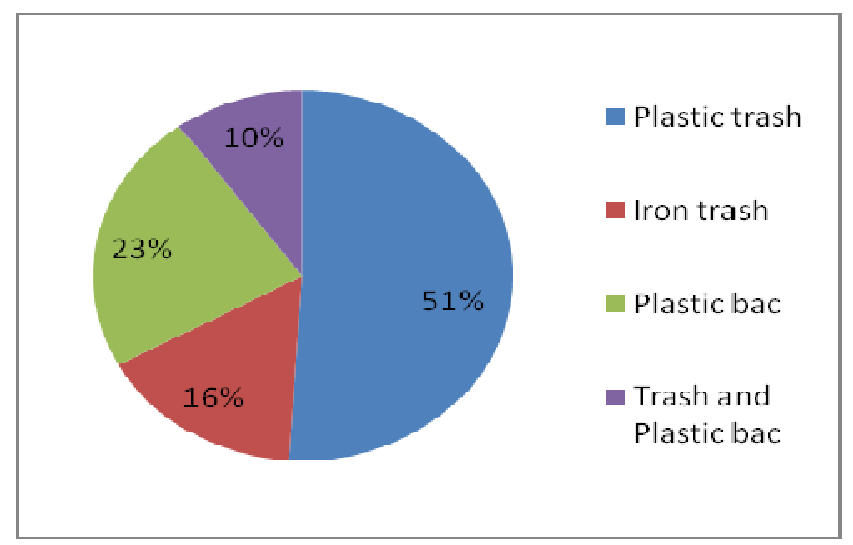

Figure 2. Percentage utilization of regulatory garbage in residential areas Almadies. 


\subsection{Unconventional Bins}

A bin is called unconventional when it does not obey the regulations and health standards. A container used to store garbage for a household plays the trash function. This is usually cooking utensils out of use, old basin, old buckets, baskets, boxes, even, cut bottles, etc. These containers are called non-regulatory garbage. His condition is open and in poor quality. This is most often use rudimentary utensil. It usually meets at Ngor village. Investigations show that there are households that do not have conventional garbage. In Ngor the majority of respondents do not have conventional garbage. Households that have them, use them for any other purpose. We will illustrate this in different. In addition to service to keep water, rice, bins are arranged to keep electrical equipment, coal, dirty clothes. We noted that households do not hold regulatory garbage but well preserved garbage. These spare keep garbage in empty paint buckets with lids in a corner of the house.

The surveys show that a household in Ngor village does not have conventional bins because the price is considered too high sometime. For others, regular flights garbage push mostly households to use utensils (76\%) already used that do not meet specified standards of regulatory garbage. In Ngor village, only $7 \%$ of surveyed concessions have regulatory dustbin. Reasons advanced by the surveyed populations, for the use of regulatory bins are most often that after collecting the garbage throw the garbage without vigilance. To this end, the garbage to break as the passage of the bucket and then become unusable. Empty bag, sachets and cartons are used for packaging waste in concessions. They are represented in the $17 \%$. In sum, all of the surveyed concessions in residential areas and at Ngor Island have met the target for the use of regulatory garbage. Within two spaces, people tell us that the use of conventional garbage savings miscalculations that may be related to bad odors and flies in the garbage. By cons in Ngor village, the high cost of garbage that people do not have them.

\subsection{The Production of Waste as Households Interviewed}

One of the characteristics of our companies is the production volume of waste of all kinds. A figure provided by the CADAK estimated production of household waste per person in the city of Dakar to $0.5 \mathrm{~kg}$ per day. It is consistent with the estimate that was made by WHO, because within the range 0.4 to $0.8 \mathrm{~kg} /$ capita / day. In the city of Dakar, the volume of waste is estimated between 400 and 800 tons per day. Despite these large numbers, the collection rate is estimated at $75 \%$. In Ngor, production is 10,9 tons per day. Daily waste generation in the households surveyed is provided in Figures 8 and Figure 9 for the residential areas of Almadies.

The production of household waste is important in the surveyed districts but varies from one area to another. However, in the traditional village varies between a bucket and a basin more (Figure 3).

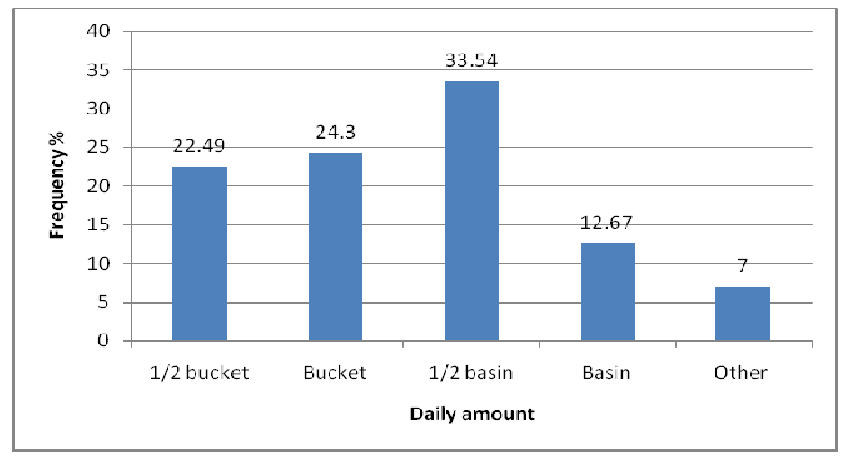

Figure 3. Estimated production Garbage Ngor Village.

Figure 3 provides information on the amount of garbage produced in residential neighborhoods Almadies (QRA). Quantification of municipal solid waste was made with a regulatory dustbin (garbage bags). We noted that the populations of users do not use utensils. The use of conventional bins is more common. The amount of junk is different in the residential area. In these areas the production is close to half $1 / 2$ and $1 / 2$ trash bag $50 \mathrm{~L}$. Production is according to the number of persons in the concession.

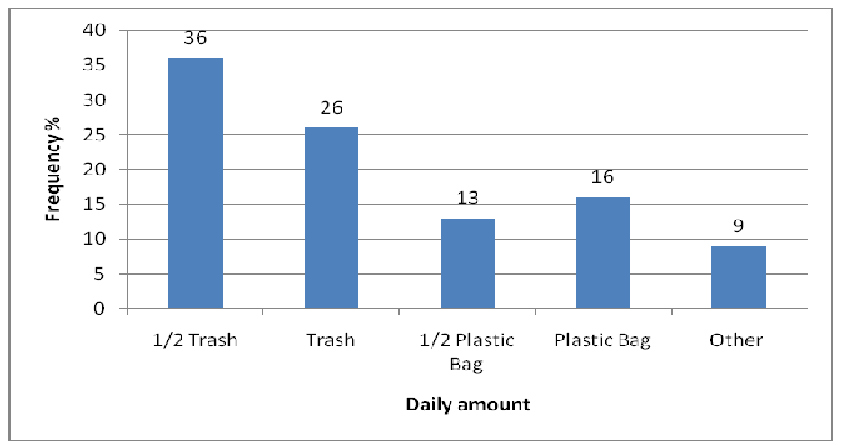

Figure 4. Estimated production of garbage in residential neighborhoods Almadies.

Figure 4 shows the number of people living in a concession.

Surveys in different areas (Ngor village, residential Almadies and Ngor Island) show that the number of people by concessions varies from one district to another. We can show that at the village of Ngor the number of people living in a house is more important compared to Almadies. The number of people in houses in residential neighborhoods does not exceed ten. In the island of Ngor the number of people does not exceed four. As the number of occupants is important more waste is important. Garbage is then stored in bins (see home conditioning). The annual amount of waste produced does not diminish. The cause lies in the multiplicity of package types, especially those used for packaging food products. But also to changes in the consumption pattern, which favors disposable products or low life. The Food monitoring is carried out in the district of Municipality Ngor shows that first town wastes consist primarily of sand, biodegradable materials and plastics. 


\subsection{Organizing the Collection in Ngor}

Garbage collection is one of the priority tasks of any municipality. This requires adequate equipment, diligent and efficient staff and a general waste policy (still in force). The municipality of Dakar handles garbage collection. It entrusts this task to the CADAK CAR (Dakar agglomerations Community -CADAK- Community agglomerations of Rufisque -CAR-) that divides the department into zones. To this end, a dealer is assigned to each zone to ensure the daily collection. In turn, in the district of Municipality of Ngor, the collection is organized into nine circuits. At follow-up, collection, we realized that there was a priority and daily tour. For the rest of the circuits, the collection is performed at intervals of two to three days. The circuits refer to the collection of the type "door to door". In addition to tours, we have the assembly points by voluntary contributions of populations.

\subsubsection{The Collection in Ngor Village}

A town Ngor collection is done by personal contribution to the point of grouping or collection "door to door". The assembly point is usually located in a part of Ngor village without any prior study, no protection against animals and without measuring leachate treatment. The majority of households Ngor village come voluntarily deposit their garbage to collection point. There is no development, the responsibility to dispose of garbage abandoned waste anywhere. Today the collection point no longer exists.

The vehicle can't make the collection "door to door" in the entire area of Ngor village because of the narrow streets and neighborhoods inaccessibility. The collection "door to door" is very limited at the large area Ngor entering village and Diogorann (Figure 5). For this reason, the age range of 10 and 13 who are responsible usually take out the trash. Figure 7 provides information on the share of different categories of people who engage in the task.

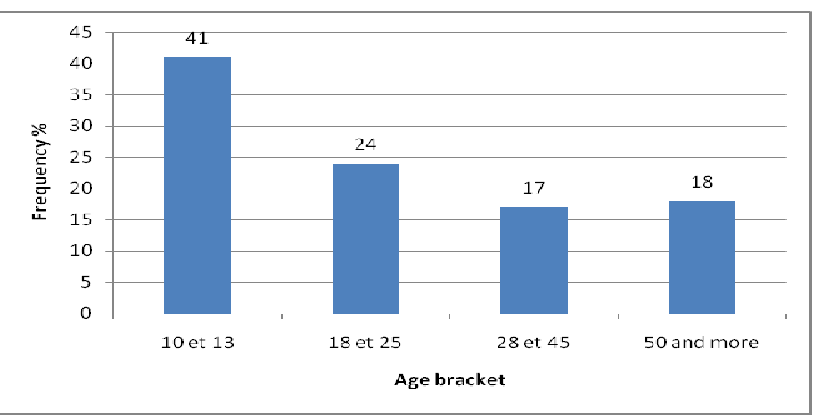

Figure 5. Responsible for waste disposal.

\subsubsection{The Collection of Municipal Solid Waste in Residential Areas Almadies}

It occurs when the garbage collectors operate at home to take the waste. Cars drive in accessible areas; the collection is home. This collection method is performed in Grand Ngor. The packer vehicle passes at home honking and making regular stops 1 to 2 minutes at most. These stops enable people to take out the trash to empty the collection vehicle. Carters are also collecting "door to door" by serving mostly areas where garbage collection is not done on a daily basis.

\subsubsection{Waste Collection in the Island of Ngor}

In the island of Ngor, there is no collection system. In the island we have noted that three households who live there all year. Waste generation is variable from one house to another. It consists mainly of green waste from gardens. We noted a household that does the sort his garbage: recoverable are stored in a drawer (pending the purchaser), biodegradable are buried in the garden (for producing composts) while the rest (residual waste) will in the garbage. The sorting by the household has contributed to the reduction of waste to the trash. Besides the permanent households on the island, we noted the presence of tourists (domestic and foreign). They participate in the production of waste managed by the association of sunbathers.

\subsection{The Collection Routes}

The municipal solid waste management system requires good organization that has several aspects from production to landfilling municipal solid waste. During the redevelopment of residential Almadies, it was cut into several zones. Figure 6 shows the zoning carried out in the Commune Borough Ngor, in the part of residential Almadies. This zoning facilitates addressing and identification of the collection circuits.

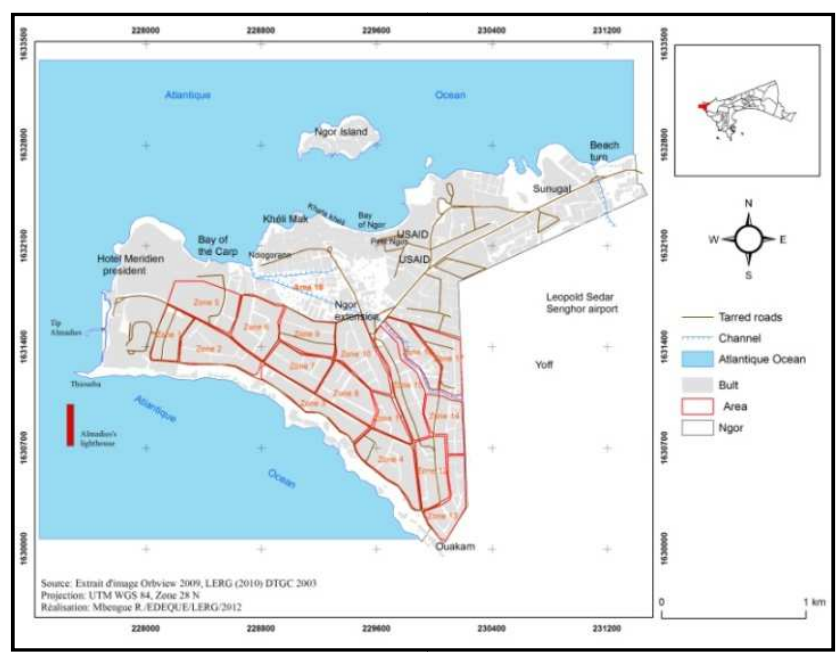

Figure 6. Zoning Almadies.

To ensure the daily collection, the dealer has divided the town in district nine collection routes (Figure 7). These are: Presidential Almadies circuit; Airport presidential system, the circuit "Darou Rakhmati" 1 and 2, the circuit WHO (World Health Organization), Pape Diop tour; Regional Council circuit, the circuit Ameth FALL Braya village of Ngor circuit and system "Diouli Kaay." The different channels are provided by the concessionaire with its logistic means. The dealer is responsible for collecting, evacuating, transporting household waste and landfill disposal.

Each circuit has a team of at least five collection agents. The trucks are not assigned to a specific circuit. The distribution of collection routes is made by the team leader from the entrance 
of the village of Ngor. This raises the problem of regularity in terms of hours of daily collection itself.

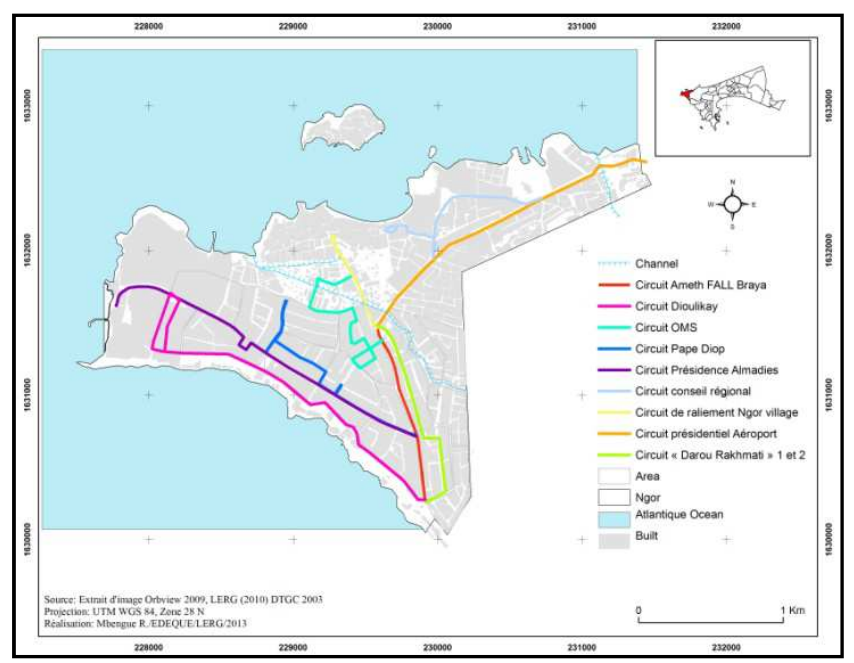

Figure 7. All collection routes to Ngor.

In the area we noted the existence of wild garbage dumps (Figure 8). Figure 11 provides information on the different routes taken by collectors every day. It also shows the main points of collection of the Commune.

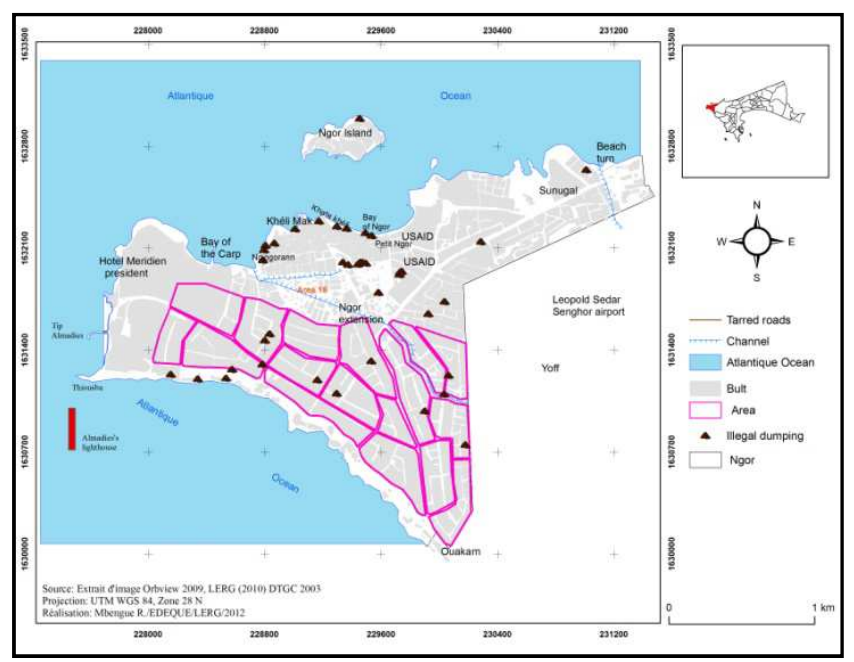

Figure 8. Location illegal dumping.

The garbage scavengers at the time of collection were with them tied bags in the back of the truck to put waste there they took. We have listed collection points and collection areas. In Figure 9 we have wild rubbish dumps on spaces collected daily. During follow-up, we noted the presence of filth on the road. The reason is that the "boudioumang" dump the garbage to search the one hand, and the carters come to lay waste they collected other.

Besides the collection points, we have illegal dumping of garbage (Figure 10). According to the team leader: illegal dumping rated around collection sites result from a overnight production (restaurants, bars, hotels); illegal dumping are the work of the carters who, having picked up the gardens of waste coming drop along the circuit "Presidential Almadies" knowing that collectors do not dare let it develop wild deposits; Deposits originate skimmers that dump the garbage when they dig in search of recyclable material.

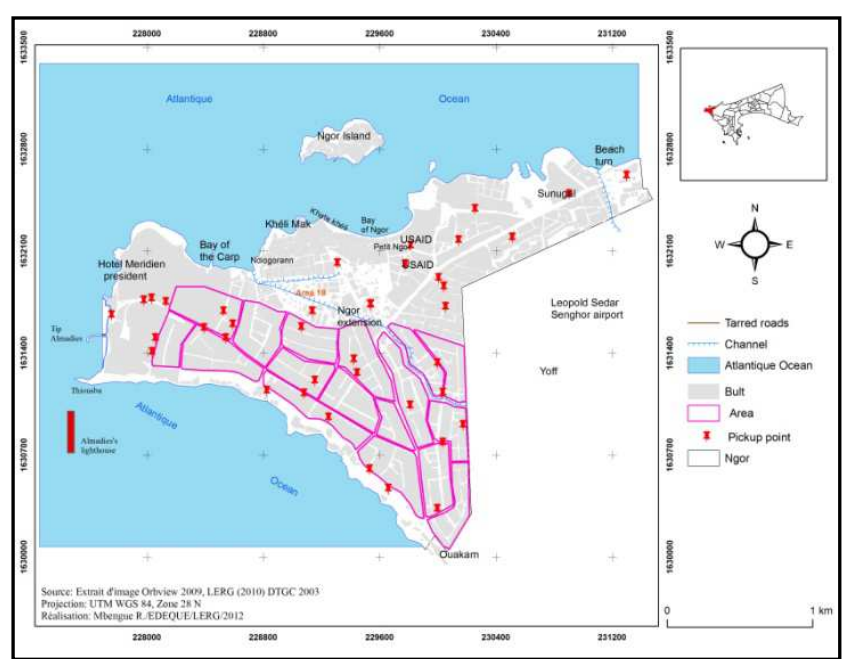

Figure 9. Materialization of collection points.

Finally, it is the work of garbage evacuation officials in homes that also come to lay waste. During the collection, the bags are hung on the ends of the vehicle. These bags are used to collect items such as bottles, utensils (butter jars, buckets, etc.). For example, scavengers recover glass bottles and sell them afterwards. Following the daily monitoring, we accompanied the bucket until the Mbeubeuss landfill where the final processing of waste is done evacuated. Figure 11, we take into account the distance covered by the collection vehicles towards the discharge Mbeubeuss.

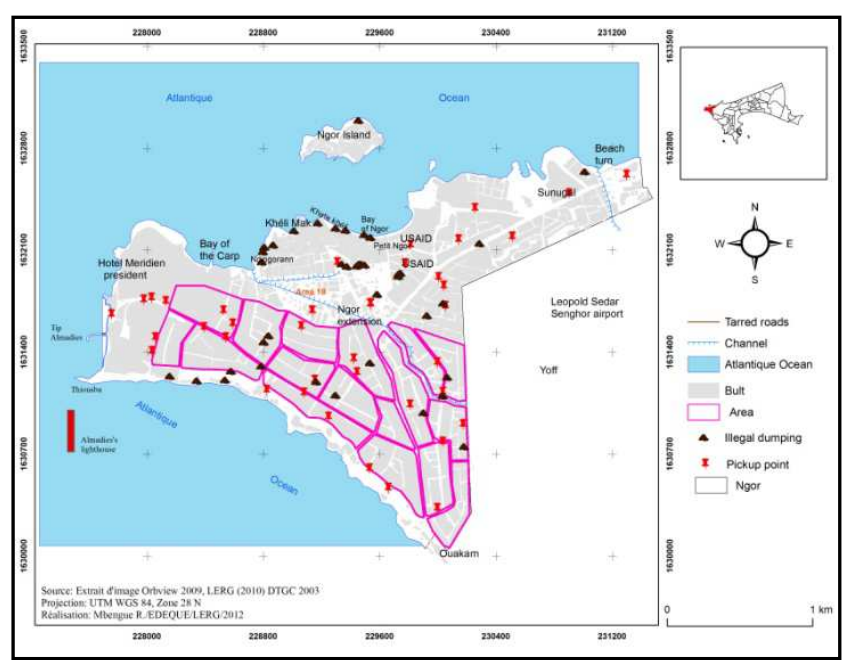

Figure 10. Location of junk deposits wild collection points.

\section{Trajectory Ngor-Mbeubeuss}

Following the daily monitoring, the garbage transport waste to the landfill Mbeubeuss. The Ngor journey to the place of storage of garbage made $29,7 \mathrm{~km}$ away. At the end of the daily monitoring, dump leaves at $14 \mathrm{~h} 02 \mathrm{mn}$ Ngor to reach Mbeubeuss at $15 \mathrm{~h} 30 \mathrm{~min}$. In Figure 13, there is materialized 
the path from Ngor to Mbeubeuss.

The follow-collector that has performed at Ngor Mbeubeuss showed that it is impossible for the packer vehicle to make more than one trip a day. The drivers we have indicated that the path that goes to Ngor Mbeubeuss is the longest made by collection vehicles in the Dakar region. During this trip, the vehicle is often caught in traffic jams. It follows a long line for weighing. Once in the landfill, the truck is facing the problem of space for dumping garbage at the platform.

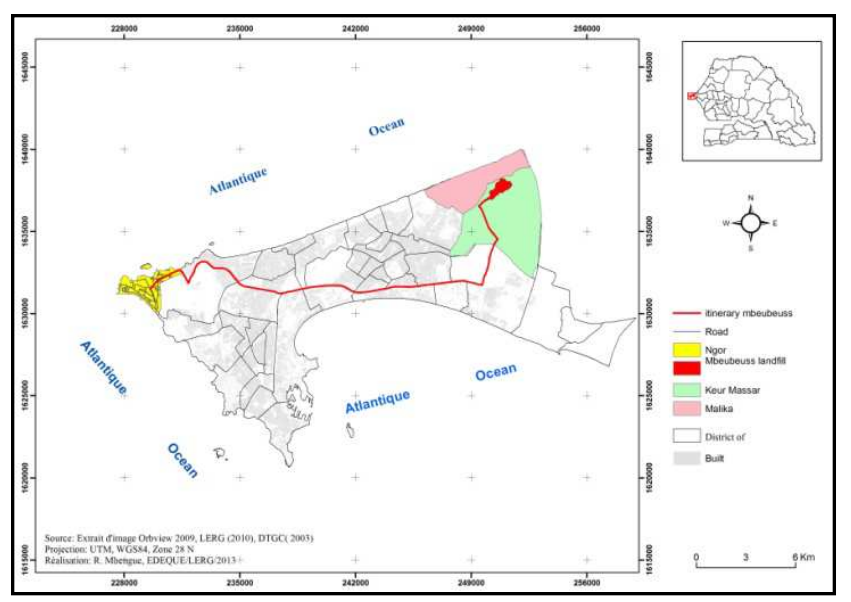

Figure 11. Ngor path to Mbeubeuss.

\section{Discussion}

Analysis of mapping the management of household solid waste has helped highlight several major events has a strong influence on the collection of garbage on the coast of Ngor. This is firstly the lack of training in how garbage collectors to collect household waste, the lack of collection points to the lack of awareness among people about environmental risks. On the other hand, the complexity of the journey Ngor Mbeubeuss which does not facilitate the collection vehicle to make more than one trip. The distance to Ngor Mbeubeuss is about 29.7 kilometers (Figure 13). Add to this the long line at deck level switches for weighing the waste to go. Another weighing is carried out to check if the truck is empty. The second weighing has become a requirement for vehicles. For some vehicles were weighed two for one load to make more money at the end of the month. The operator is paid for the daily tonnage spilled Mbeubeuss. The District Municipality is to facilitate the collection in areas that are not accessible (Diogorann, KhataKhéli and Petit Ngor) (Figure 1) to establish points of combinations. To do this, bins large capacities must be implemented in locations defined by the municipal authorities. With the strong presence of business units (services, shops). The limitations of this study reside on the scarcity of data on the complete waste. Their reliability often can't be determined. Because of the wide range of factors affecting waste will always be difficult to quantify.

Other authors have shown that the high concentration of people in the city of Cotonou [19] results from the high concentration of administrative, commercial and economic activities. The complexity and diversity of problems involved have not enabled the municipality of Cotonou effectively identify and control the management of the waste produced in that territorial division. [20] Shows that the problem of waste management is a global problem [21]. If collection strategies have collection have been adopted in some areas, stresses occur in others (narrow, sandy area). According [22], the causes of environmental problems are multiple and diverse. In this regard, the international community and scientists were invited to the summit in Rio de Janeiro to take steps to better control the impact of human activities on the environment. [23] Showed that people in developing countries are not too educated on the management of the living environment. They leave trash anywhere, creating the disfigurement empty spaces, streets, and alleys [24]; [7]. These acts do not reflect a good education, a good education or related information. This situation is similar to that found in the Commune of Ngor. [25], meanwhile shows that there was no coherence and cooperation in local strategies. No responsibility was placed on the collection of industrial waste beyond the obligation to pay tax on their resource. In 1996 [26]; [27] some British environmentalists had been committed, they should plan to review the tax that could help increase waste reduction with funding to minimize environmental risks. In this same vein, [28]; [29]; [30] discuss that in addition to problems related to garbage dumps, there are difficulties in the collection of electronic waste and recovery.

The results we presented suggest that waste management should be primarily a concern of the Municipality. This should encourage the establishment of some organizations such as the so-called community-based, neighborhood committees and women's groups. They suggest that the Municipality must, to facilitate collection in inaccessible areas (Ngodioran, KhataKhéli and Petit Ngor) establish points of combinations. To do this, bins large capacities must be implemented in locations defined by the municipal authorities. With the strong presence of business units (services, shops). We propose the establishment of the program to fight against environmental threats. This strategy aims to protect the living environment of the populations and their natural space. However, it should be noted that efforts are about to be made by the Government of Senegal as part of the management of urban solid waste in Dakar. Coordination of actors and advocacy population becomes a necessity for leaders of the sector.

\section{Conclusion}

Ngor recorded an increase in its production of household solid waste. Illegal dumping becoming widespread, both in Ngor village in residential areas of Almadies. This led the government to seriously address the issue of waste management by adopting a specific law to the Senegalese capital (Dakar). This law aims at improving the overall quality of the waste management service and, by extension, the quality of the environment and public health. The evaluation of this new integrated waste management policy by CADAK $\mathrm{CAR}$, allowed us to note that efforts have been made in the 
field of cleaning. Dealers have taken their place in the collection and disposal of household waste. Garbage collectors trying to eradicate wild dumps in the town district, acquire new equipment and reinforcement of staff. However, some limits were observed in the management of household waste by concession operators. They sometimes have preferences as to the areas to collect because of the tonnage price. During our investigations, we have often witnessed changes in areas in search of waste to be collected. This allows for a greater amount of waste and get more money. The payment to the tonnage of concession companies is an obstacle to good management of solid waste in the city of Dakar. The dealer asks to change zone when he realizes that the tonnage at the end of the month decreases. In Ngor, we attended the concession changes related to this problem. This is also due to the fact of the existence of the weight of sand in other areas which contributes to the increase in tonnage. We can remember the example of the area of Grand Yoff, Parcelles Assainies, Guédiawaye etc. who choose the dealers.

Furthermore, measures must be taken to the generalization of selective sorting by households. Thus, the role of each actor must be well defined. First, all stakeholders must be clearly defined and individual skills well established. Kinds of spaces with specific equipment must be set up to facilitate the collection and sorting support. Sorting for paper, glass, plastic, metal, etc. its generalization allows setting up recycling / recovery processes. Indeed, the participation of households in sorting is the key to success of any policy to reduce at source. It also reduces the amount of junk in to put in the trash and costs in transport. Awareness raising and information campaigns within households to encourage them to make an effort in the sorting is essential. The realization of the sorting will allow, firstly, the reduction of landfill waste, on the other hand, the increase in packaging waste to be recovered. Finally, we can hold that for good governance in the management of household waste, household participation should be generalized. This allows them to feel involved in the collection system and waste disposal. Households sabotage collection by dumping garbage anywhere ignoring the risks on their own health and their environment. For this purpose, involvement and participation of households in the collection process is required. People must be educated to the extent that environmental management is not just for Municipal Stakeholders. By reducing the degradation of the environment, we will also decrease the expenses for public health.

\section{References}

[1] Julien Rouyat Cecile Broutin, Virginia Rachmuhl Ahmed Gueye, Valentin, Torrasani Ibrahima Ka, STUDIES AND WORK ONLINE EDITION \# 8 GRET, WWW.Org 2006: Household Waste Management in Secondary Cities of Senegal towards Policies including municipal suburbs. 91 pages.

[2] ADEME, 2000, 2nd edition Municipal waste. ADEME Editions, Paris, $11 \mathrm{p}$.
[3] Ericson, O., Carlsson Reich, M., Frostell, B., Bjorklund, A., Assefa, G., Sundqvist, J.O., Granath, J., Baky, A., Thyselius, L., 2005. Municipal solid waste management from a system perspective. Journal of Cleaner Production 13, 241-252.

[4] Kapepula, KM, 2006. Contribution to the improvement of the management ofmenagers solid fuel waste in the cities of developing countries. The Dakar Senegal case. Doctoral These, University of Liege, Belgium.

[5] APROSEN, 2006, National Strategy for integrated and sustainable solid waste management in local authorities, GES-Concil, Dakar, 87 p.

[6] CADAK-CAR, May 2007: Executive Summary on the Urban Waste Management Program Solid in the Dakar region, and IAGU CADAK-CAR, $15 \mathrm{p}$.

[7] Cisse O., 2012, garbage dumps Mbeubeuss in Africa in Dakar, Senegal, Karthala, 329 p.

[8] Mbengue R., 2010: Management And Environmental Impacts Of Municipal Solid Waste In The Municipality District Of Ngor, Master Dissertation 2 Gidel, Department Of Geography Ucad, 75 Pages.

[9] Adepoju G. O, 2001, urban waste management. Solutions for Africa, and IDRC Ed Karthala, Paris, 250 p.

[10] Bihidindi André: 2002: Sustainable Waste Management in Urban State and Perspectives for a Vietnam technology transfer in Senegal for the recycling of waste. DEA, ATEGU, ENEA Dakar, 95 pages + annex.

[11] Sidibe C., 2013, Articulate conventional and unconventional waste management in the Dakar region: a contemporary challenge. Master Thesis 2; Geography and Planning University of Maine-Le Mans-Laval, Faculty of Arts, Languages and Human Sciences, 105 p.

[12] Wane OA 1981 Contribution to the study of the environment in Senegal. Waste Materials and urban disparities in an African city: Dakar, PhD 3rd cycle, urban planning and development specialist, mention Planning and Environment, ISE, FST, UCAD, $382 \mathrm{p}$.

[13] Onibokun Ag, 1989 The Governance Of Waste Africas: The Example Of Cairo, Dakar And Nairobi, Karthala, Idrc, 254 P.

[14] Wass E. 1992: Municipal waste, waste plural In introductory remarks waste and Men: Environment African. pp. 7-20 Ibid.

[15] A. Hebette: 1996 Practical Guide to the management of urban solid waste in Sub-Saharan Africa World Bank CREA-AO 151 pages.

[16] Coulibaly, GMMZ1997, Domestic Production, Recovery and Recycling of waste plastics; Cases of plastic waste in Dakar, 3rd cycle doctorate in environmental sciences, ISE, UCAD, FST, $141 \mathrm{p}$.

[17] Nouvel Horizon, 2007, Http/www.Seneweb.com

[18] Mbengue R., 2009: Problems in the collection of household solid waste in the town of Kaolack, Master's Dissertation UCAD Department of Geography, 152 pages.

[19] CREPA-BENIN. 2006, In ecological sanitation in West Africa and the Centre for an effective contribution to achieving the Millennium Development Goals. Countries concerned, Benin, Burkina Faso, Congo, Côte d'Ivoire, Guinea Conakry, Guinea Bissau, Mali, Niger, Senegal, Togo. Project document, 51 p. 
[20] Cisse O. \& S. WONE S 2013, the management of waste in Dakar (2000-2012) institutional imbroglio. Momar-Coumba Diop (dir), CRES-Karthala, (2012) pp 759-788

[21] D. Dietman 2008 Household waste. The garden impostors. Edition Harmattan, 160 P., P10 to 68.

[22] Thibault V., 2001, Environment and Urban Development, Sanitation and Household Waste Management in the city of Thies (Senegal). Internship memory, Strasbourg, 122 p.

[23] Onibokum AG 2000, urban waste management: solutions for Africa, IDRC - Karthala, 238 p.

[24] Ba IS, 2008, Issues and solid waste management strategy: Example of Nouakchott (Mauritania), end of study thesis, ISE / $\mathrm{UCAD}, 85 \mathrm{p}$.

[25] Boyle CA management in New Zealand Solid Waste Management 20 (2000) pp517-526 CADAK-CAR, May 2007: Executive Summary on the Urban Waste Management Program Solid in the Dakar region, and IAGU CADAK-CAR, 15 p.
[26] Robert M 1996: soil interface for the environment. Resource Development. Edition Masson, Paris, France, 242 p.

[27] Attahi B.1996 Sustainable Management Research Program of waste and urban sanitation, An anthropology of the mire. Defilement of the city with sewage and excreta in Ouagadougou and Bobo-Dioulasso (Burkina Faso), Research Action 4, SHADYC (Marseille) GRILL (Ouagadougou), 224 p.

[28] Djitte M., 2010, the management and development of computer equipment waste in Senegal: Diagnosis and proposal of a suitable legal and institutional framework. End of study memory, ISE / UCAD, 99 p.

[29] Mbayu Kapepula b, Gerard Colson a, ${ }^{*}$ Karim Sabri b, Philippe Thonart c, 2006, A multiple criteria analysis for household solid waste management in the urban community of Dakar. Waste Management 27 (2007) 1690-1705

[30] Cisse O. 2007 waste money. The informal economy in Dakar, and CREPOS Karthala, 165 ; 